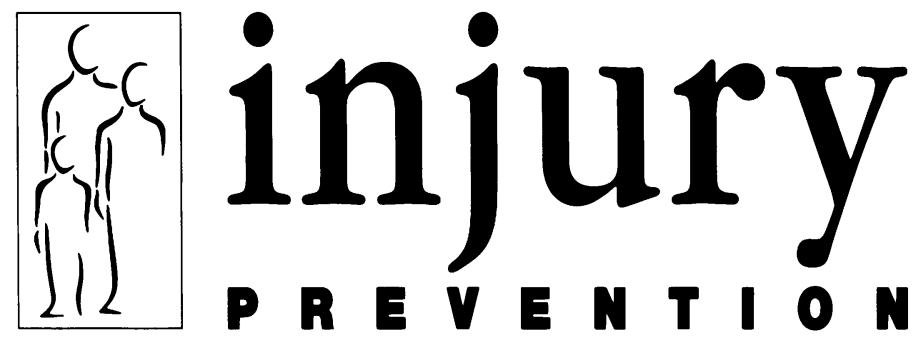

Journal of the International Society for Child and Adolescent Injury Prevention

\title{
Editorial
}

\section{A modest proposal}

Jonathan Swift, the 18th century Irish writer, wrote a satirical tract titled 'A modest proposal for preventing the children of poor people from being a burden to their parents or the country, and for making them beneficial to the public' (1729). Swift proposed that Irish children be raised for meat; an ironic suggestion intended to call attention to the impoverishment of the Irish because of high taxes and cruel landlords. My idea is much more modest and arises from a conviction that the time has come to try to get others to practice what I have been preaching. Periodically I agonize about the relationship - or more properly, the relative lack thereof - between research and its implementation. In injury pevention, this gap is especially tragic because, as Rivara has estimated, ${ }^{1}$ if all we have learned were fully implemented about $30 \%$ more lives would be saved.

As matters now stand, the link between research and its various applications remains haphazard. Sometimes it is there and sometimes it is not. Most often, the time until findings get applied is much longer than it should be. Too often, it hinges on an unusual researcher with the wit or wisdom to take the findings to the right people, at the right time, properly packaged and hand delivered. That is what Hugh Jackson did with child resistant containers, what Ken Feldman did with tap water scalds, and what Seymour Charles did with seat restraints.

But we can't all be like them. Most researchers are plodders who have thought little about what happens to the results once they are published. To remedy this, I propose that when a project is completed, and even before it is published, each investigator (or better still, the galaxy of coauthors) take the time to do the following:

(1) Find one result that has a clear message for prevention. I encourage authors to conclude papers in this journal with a section along these lines, but am not always successful. This may be because researchers are either too modest, too scientific, or both. They tend to be reluctant to see implementation opportunities - especially from a single study, or one with inconclusive results, or if they view the study as 'only descriptive'. To them I say, 'Set modesty aside. Let your imagination run free. Think laterally. Give the benefit of the doubt to any reasonable idea about how the findings might be applied'.

(2) Once you have come up with some such ideas, find someone who can act on them. This, too, is easier said than done. It is often difficult to know who does what these days, especially in government where much of the hoped-for action lies. Nevertheless, researchers must always consider explaining their findings to colleagues at the nearest community based prevention program. Frequently, this will prove to be the first time researcher A will have met program person B. I predict that something beneficial to both parties will follow, and not only from the study in question.

(3) After the researcher has isolated the prevention message, and identified a potential user, he or she should then arrange to meet for a coffee or tea, or, if necessary, by telephone. The goal is to foster a personal relationship between the researcher and someone on the front line with responsibility for prevention. If that 'someone' is unable to use the findings, they are likely to know others who can.

It all sounds simple, yet it comes from years of reflection (which may simply prove that I'm a very slow thinker). Maybe because it is too simple and won't work. But I urge you to give it a try. Behind this proposal is the conviction that although direct communication of this kind is rare, when it happens, the results are often surprising. Even when it is a 'no go' for a particular project, it lays groundwork for the future. The link arising from such meetings can lead to other benefits for both parties. As in the imagined dialogue in Hayes' editorial in a previous issue, I envision a conversation along the following lines:

Researcher: 'I just published a paper on falls from heights in that wonderful journal, Injury Prevention, and I want to ask you if you are interested in what we found?'

Program/policy person: 'That all depends on what it is'.

Researcher: 'Well I'm not sure we have proven anything, but we think our findings suggest that it might help if pressure were brought to bear on the authorities to ensure that windows, especially in poor areas, and especially in the warm weather, were protected by some sort of guards so children can't fall out of them'.

Program/policy person: 'Of course, that makes sense and we will certainly do what we can to promote the idea. We'll begin by summarizing your findings in our newsletter, and maybe organize a letter writing campaign directed at the Minister. But why don't you ring up Philip Broom, the Minister of Housing, yourself? He's an old friend. His number is $935-9264$ '.

Researcher: 'Gee, I don't know. Do you think the 
Minister would be interested? After all, I haven't proven anything'.

Program/policy person: 'Well, I don't know either, but why not give it a try? And, by the way, while you're here and now that we've finally met, I wonder if I can interest you in a project we've been thinking about. I, too, read that marvellous journal, Injury Prevention. They keep on about evaluating new programs. But we don't have the resources, knowledge, or skills to do it. Would you help?'

Researcher: 'Maybe. It so happens I have this bright grad student who is looking for a project. An evaluation project might interest her. If not I'll ask around. Even if we can't link up on this project, perhaps we can work together on another right from the start. After all, they say that is the way these things get done'.

Program/policy person: 'That would be wonderful, wouldn't it?' (... fade out to the sound of Louis Armstrong singing What a Wonderful World).

IB PLESS Editor

1 Rivara FP, Grossman DC. Prevention of traumatic deaths to children in the United States: how far have we come and where do we need to go? Pediatrics 1996; 97: 6.

\section{Guest editorials}

\section{Postmarketing surveillance of injury countermeasures}

Postmarketing surveillance is a procedure to monitor use of a drug or other therapeutic agent after it has been licensed for general use, and particularly the occurrence of associated adverse effects. ${ }^{1}$ With the burgeoning pharmacopoaia available to physicians, and with increasing concern about therapeutic adverse effects, postmarketing surveillance has become a vital component of the evaluation of antidisease interventions. Even large scale clinical trials cannot emulate the use of therapeutic agents after general marketing. Sample sizes of such trials are never adequate to reliably determine the risk of rare adverse events. Trial conditions are also often different to those seen with use in the general community, where compliance, drug interactions, prescriber variation in dose and indication, and other factors operate together to potentially modify the expected benefits and disadvantages of a particular drug or vaccine.

The same applies to injury countermeasures, which represent a broad range of techniques including engineering solutions (vehicle passenger restraints, domestic swimming pool enclosures and self closing/locking gates, bicycle helmets, etc), consumer product design solutions (nonflammable textiles for children's sleepware, poison cabinet locks, curly cords, etc), restricted access to hazardous products (hand guns and automatic/semiautomatic weapons, child resistant closures, etc), and education programs, to name a few. In addition, we have developed ways to package or implement these solutions. The principle tools are social marketing, legislation, enforcement, and community development. Few would disagree that all such interventions should be subject to rigorous effectiveness evaluation. And postmarketing surveillance is equally important.

In general, injury countermeasure postmarketing surveillance should aim to monitor both the intended and the unintended effects of the countermeasure. Various injury surveillance systems can be used to achieve this end, and they are. For example, the progressive strategy during the $1980 \mathrm{~s}$ in Victoria to introduce bicycle helmet use culminating in legislated compulsory helmet use for all from July 1991 was shown to be associated with a similarly progressive reduction in the incidence of head injuries to bicyclists. ${ }^{2}$ Statewide hospital inpatient data, data from sentinel injury surveillance systems for emergency department treated injuries, and police, road authority, and traffic insurance claim sources were all employed to monitor the impact of promotion strategies and then the law.

Early postmarketing surveillance after the introduction of Victoria's helmet law showed that bicycle usage fell, accounting for a proportion of the post-law drop in head injury incidence. ${ }^{3}$ Opponents of such legislation elsewhere are now arguing that this reduction in cycling is an undesirable and unintended effect that will have a broader and more significant adverse health impact on cardiovascular disease through exercise reduction. ${ }^{4}$ Such opponents of a helmet law have so far failed to quantitatively demonstrate whether this might be the case given levels of bicycle use and forms of alternate transportation used by those who might not wish to use a helmet (for example, walking). But, injury researchers have also failed to demonstrate whether the observed reduction has persisted after the early period studied.

It is also important to monitor the extent to which the intervention has been applied (including the application of enforcement). This permits the linking of the intervention to relevant injury outcomes. In Queensland in the early 1990 s, after many years of promotion, education, and agitation, the state government mandated domestic swimming pool enclosures for both new and existing pools. Subsequently, there was a steep drop in toddler drownings. However, there has been no survey of the extent to which compliance with the law has occurred, and it is not known how many pools have been protected. To be sure, those post-law drownings which have occurred have been carefully studied, and the absence of a functioning, standards compliant fence and gate has been noted for virtually every immersion death (Robert Pitt, personal communication). Elsewhere in Australia, attempts to introduce similar legislation have been hampered by our failure to demonstrate widespread implementation of protective enclosures. Opponents have consistently argued that observed reductions in drowning are merely the result of media attention to drowning risk for toddlers, and consequent improve- 